\title{
SUSTAINABILITY OF THE SMALL BUSINESS ENVIRONMENT IN ROMANIA IN THE CONTEXT OF INCREASING ECONOMIC COMPETITIVENESS
}

\author{
Cristina Maria BĂTUȘARU \\ "Nicolae Bălcescu” Land Forces Academy, Sibiu, Romania, batusaru.cristina@gmail.com
}

\begin{abstract}
Ensuring a sustainable management in the field of SMEs is an essential condition of the market economy and is the premise of an efficient and successful collaboration between the public and the private environment. The continuation of the structural reforms meant to support the mechanisms of the competitive economy represents an essential condition of the Romanian state in its social-economic development efforts. Considering the role of the SME sector in ensuring a favorable climate for the national economic progress, this paper addresses a quantitative and qualitative analysis of the small business sector in Romania, aiming to identify the main challenges that the Romanian state faced during the period 2008-2017. This analysis aimed to establish the main weaknesses and strengths that Romania has demonstrated during the period analyzed in order to outline a set of recommendations that the Romanian state should follow in implementing its policies in the SME sector, in order to be ensure sustainable and prospective economic development management.
\end{abstract}

KEY WORDS: market economy, small business, competitiveness, economy

\section{INTRODUCTION}

The importance of the business environment on the national economic development determined the execution of some steps regarding the elaboration of strategies meant to support and promote the development of small and medium-sized enterprises (SMEs) in Romania. Adopting and harmonizing the business environment in the context of global economic trends requires a complex process of analysis of many elements involved such as the national economic structure, the existence of human resources, and the technical and technological infrastructure used [1].

Thus, in an era of technology and of the tendencies of establishing a global market, the main challenge encountered by the national economies participating in international trade is represented by the level of competitiveness of the companies operating in that market. Starting from this reality, the SME sector becomes a determining factor of the competitive economy, representing the main source of economic growth and development and employment.

In the last years, the SME sector in Romania has experienced quite a good development given the status of the member state of the European Union and the impact of the state's macroeconomic policies in this field [2]. Although as a country we had a heavy debut in this segment given the uncertain period of the transition and the lack of a concrete strategy in this direction, at present the SME sector has emerged as a phenomenon of the socio-economic development of the country.

In order to identify the contribution of this sector to the economic development of the country, it is necessary to analyze both quantitatively and qualitatively. This approach will give the possibility to identify the weaknesses and strengths of the SMEs in Romania and is the basis for the future directions of supporting this process from the state.

The indicators that allow to measure the quantitative impact of SMEs on the economic growth is represented by their weight in the GDP and the weight of this sector the total of the companies and the results obtained by them. From the qualitative perspective of their role on the sustainable development of the economy, the areas analyzed the sectors in which these SMEs operate. The more the tertiary sector enjoys greater representation, the more we can say that the national economy is heading towards a knowledge-based economy supported by the pillars of technical-scientific and technological progress [3].

\section{SUSTAINABILITY OF THE ROMANIAN SME SECTOR AND ITS QUANTITATIVE ANALYSIS IN THE PERIOD 2008-2017}

The Romanian economy is very well represented by the sector of small and medium-sized enterprises, these having a significant share in the totality of the companies active on the internal market. Considering the analysis period, we can see a decrease in the number of micro-enterprises in the post crisis period, these being the most affected by the market shocks, which led to the elimination of some of them. The weak economic force and the competitive capacity were the main causes of the inability to adapt to the new market conditions imposed by the outbreak of the economic crisis of 2008 .

It can be seen that the situation is starting to recover from 2012 as a result of state support for efforts to improve the regulation and support policy of the business environment. An important role in the financial support of the SME sector was played by the European funds granted during the programming period 20072013, having a special contribution to the development of entrepreneurship, especially felt among micro-enterprises.

The small and medium-sized enterprises, which remained at a relatively constant level, proved to be much more competitive. However, it must also be taken into account that their numerical representation in the total number of enterprises is much lower compared to that of micro-enterprises. 
Figure 1. The evolution of small and medium-sized enterprises in the period 2008-2017

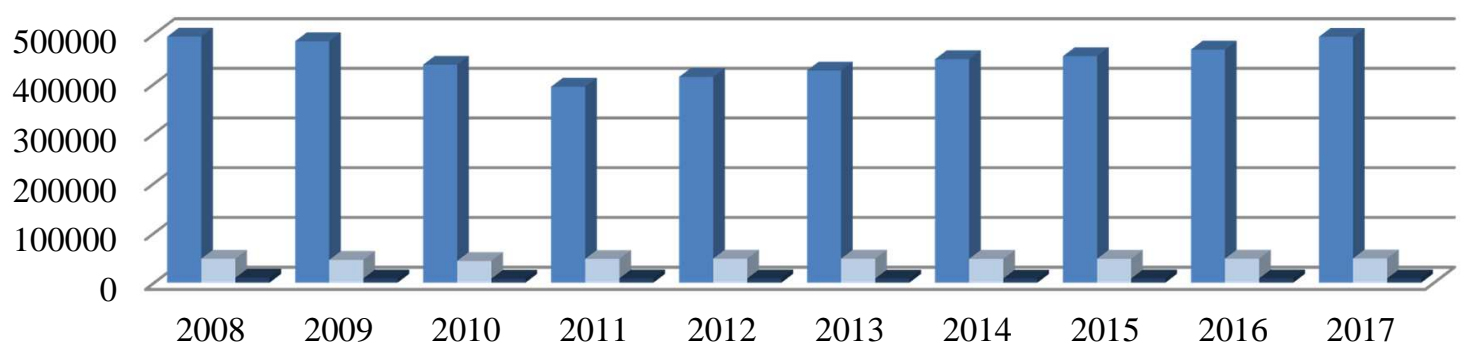

$\square$ Micro enterprises (0-9 people) $\square$ Small enterprises (10-49 people) $\square$ Medium-sized enterprises (50-249 people)

Source: National Institute of Statistics

To further capture the importance of this sector in the national economic development, it is considered important to present the main indicators that characterize the activity of SMEs.

Table 1. Evolution of the share of SMEs in the total of enterprises during 2008-2017

\begin{tabular}{|c|c|c|c|c|c|c|c|c|c|}
\hline \multirow{2}{*}{ Year } & \multicolumn{3}{|c|}{$\begin{array}{l}\text { Number of enterprises } \\
\text { (thousands) }\end{array}$} & \multicolumn{3}{|c|}{ Number of employees (thousands) } & \multicolumn{3}{|c|}{ Turnover (million lei) } \\
\hline & Total & SME & $\%$ & Total & SME & $\%$ & Total & SME & $\%$ \\
\hline 2008 & 534,5 & 533,2 & 99,8 & 554,9 & 553,1 & 99,7 & 957965,4 & 403721,4 & 42,1 \\
\hline 2009 & 519,4 & 518,6 & 99,8 & 541,6 & 540,1 & 99,7 & 855807,1 & 355278,8 & 41,5 \\
\hline 2010 & 470.1 & 469,2 & 99,8 & 491,8 & 490,2 & 99,7 & 904080,3 & 369216,6 & 40,8 \\
\hline 2011 & 430,6 & 429,6 & 99,8 & 452,1 & 450,4 & 99,6 & 1006164,6 & 397024,2 & 39,5 \\
\hline 2012 & 449,5 & 448,4 & 99,8 & 472,1 & 470,5 & 99,7 & 1062410,7 & 419903,5 & 39,5 \\
\hline 2013 & 461,4 & 460,5 & 99,8 & 485,1 & 483,4 & 99,7 & 1055352,2 & 422678,3 & 40,1 \\
\hline 2014 & 483,1 & 482,1 & 99,8 & 507,4 & 505,7 & 99,7 & 1109552,6 & 449117,5 & 40,5 \\
\hline 2015 & 488,2 & 487,1 & 99,8 & 513,8 & 512,1 & 99,7 & 1188383,5 & 483381,1 & 40,7 \\
\hline 2016 & 500,4 & 499,3 & 99,8 & 527,7 & 526,1 & 99,7 & 1235484,7 & 510518,6 & 41,3 \\
\hline 2017 & 525,6 & 524,5 & 99,8 & 553,7 & 552,1 & 99,7 & 1362545,1 & 560465,7 & 41,1 \\
\hline
\end{tabular}

It can be observed that during the analyzed period the number of SMEs as a share in the total number of enterprises registered a constant position as well as the number of employees. analyzed. This aspect draws attention to the importance of microenterprises and the role that entrepreneurship plays in the process of creating an efficient and prosperous market. The average sales revenue per company in 2017 represented approximately 1066 thousand, 28\% higher than in 2010. This result is also justified by increasing the competitiveness of the companies operating on the national market given that the number of SMEs in 2017 has not reached the level of 2010. Also, the increase of the turnover in the SME sector 2011-2013 is explained also by the participation of the Romanian companies in the European single market and the intensification of the commercial relations with the member countries of the European Union. In this sense, it is important to analyze the volume of exports by the SME sector compared to the total of the exports made by the companies operating in the economy.

Figure 2. Share of direct exports by SME categories in total exporting companies

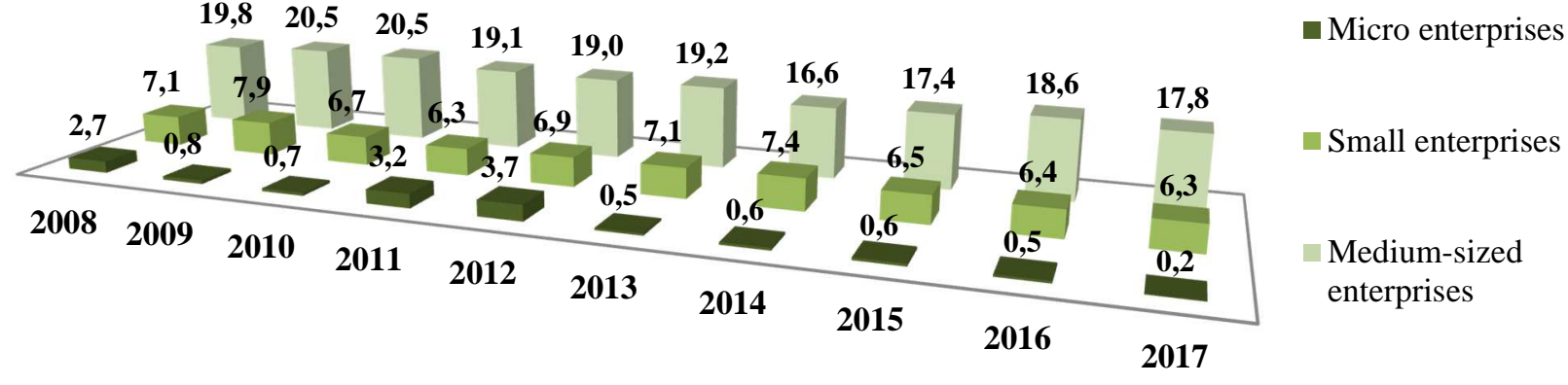


Given the significant share of SMEs in the total number of enterprises of approximately $99 \%$, the role that this sector has in the economic and social development of the country is indisputable. The SME sector provides a relatively high share of exports among enterprises, but their level of $29.6 \%$ in 2008 was not reached in any of the years of the reference period. Given the significant share of SMEs in the total number of enterprises of approximately $99 \%$, the role that this sector has in the economic and social development of the country is indisputable. The SME sector provides a relatively high share of exports among enterprises, but their level of $29.6 \%$ in 2008 was not reached in any of the reference period years. The year 2017 registered the lowest level of exports of small and medium-sized companies, about $24 \%$ of all exports. In the period 2008-2012 it can be observed that the exports made by the micro-enterprises were affected to a lesser extent than the small companies, as a result of the effects generated by the economic crisis erupted at the end of 2008. This evolution is the consequence of the flexibility of the micro-enterprises that are characterized by a higher volatility regarding the capacity of restructuring and reorientation. The period 2013-2017 is characterized by a less favorable evolution of the level of exports provided by the analyzed sector, this being largely due to the instability of the political environment and the consequences it had on the economic environment. The inconsistency and lack of predictability of state policies in fiscal and economic matters have created an unfavorable framework for the activity of SMEs. The analysis of the data in Figure 2 leads us to score some observations of relative character, because in the statistical database provided by the National Institute of Statistics there were numerous positions of confidential character especially among the small and medium enterprises regarding their export activity. Given the current trend of the SME sector in Romania, we consider that it is relevant to carry out a brief SWOT analyzes highlighting the present achievements and outlining future directions to which the state's efforts should focus in supporting this vital sector.

\subsection{SWOT analysis of the SME sector in Romania during 2010-2017}

\section{STRENGHTS:}

- Implementation of the competition policy in order to ensure an optimal climate of business activity;

- Strengthening and improving the administrative capacity of the competition and state aid supervisory authorities;

- Reforming and consolidating institutional structures by strengthening the role of employers' organizations and professional associations as partners of the public administration;

- Simplifying and reducing the bureaucracy at the entry, operation and exit of the market of commercial companies;

- Simplifying and improving the legal and administrative framework regarding the SME sector;

- Supporting organizations representing the SME sector and consulting them;
- Identification of the priorities of development and efficient allocation of resources;

- Improving the access of SMEs to financing, by optimizing the offer of services for increasing business performance;

- The geographical position of the country.

WEAKNESSES:

- Inefficient dialogue and cooperation between entrepreneurs and public authority;

- Still low level of entrepreneurial culture and vocational training in this field;

- Low level of quality of business plans benefiting from state and / or European financing;

- Imbalances of SME development in territorial profile due to the lack of adequate infrastructure;

- Low level of competitiveness of SMEs;

- Insufficient publicizing of entrepreneurship opportunities among young people.

\section{OPPORTUNITIES:}

- EU financial assistance in the field of SMEs;

- Increasing the competitiveness of national companies and developing investments in public-private partnership

- Pro-European vector in national development;

- Competitive development and internationalization of the SME sector;

- Modernization of the business environment through continuous development of innovations;

- Continuous reform in the education system to meet the demands of the labor market;

- Development of the consulting services sector in the field of entrepreneurship;

\section{THREATS:}

- Migration among young people considered as the main demanding entrepreneurs;

- Instability of fiscal policy;

- Pressure from international competition;

- Slow adaptation of the educational system to the professional demands of the labour market;

- The relatively low participation of entrepreneurs in training courses in the field of entrepreneurship.

\section{QUALITATIVE ANALYSIS OF THE SME SECTOR IN ROMANIA}

From the qualitative perspective of their role on the sustainable development of the economy, it has been analyzed the sectors in which these SMEs operate. The more the tertiary sector enjoys greater representation, the more we can say that the national economy is heading towards a knowledge-based economy supported by the pillars of technical-scientific and technological progress [4]. The Romanian economy has had an agro-industrial tradition that in the last decades has been strongly surpassed by the services sector, becoming the main engine of economic growth and employment. The evolution of the structure of SMEs by main categories of economic activities is presented in the graphs below, having as reference years 2010 and 2017, the ends of the analyzed time interval. 
Figure 3. The weight of SMEs in the main types of activity in 2010

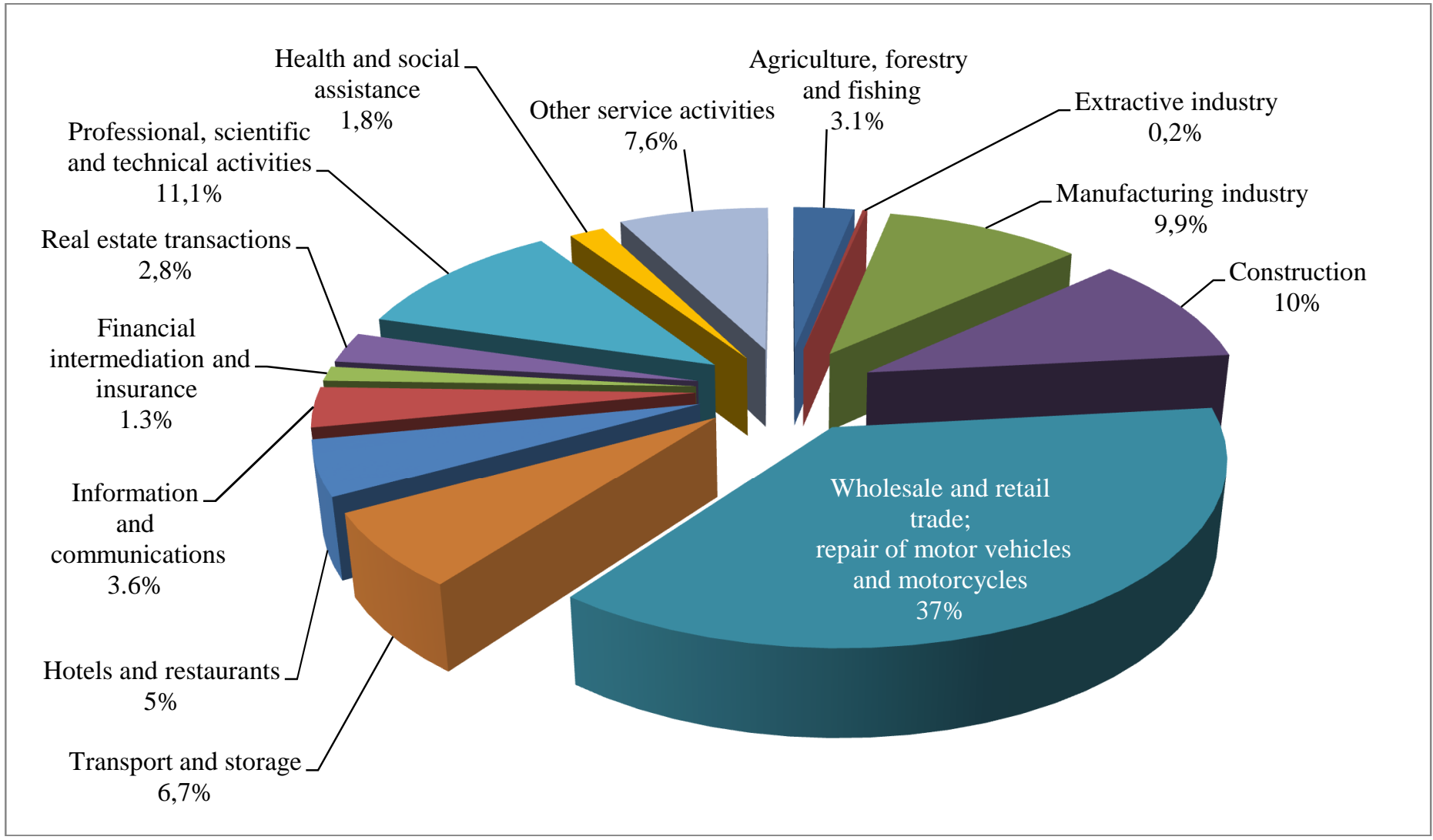

Source: National Institute of Statistics

Figure 4. The weight of SMEs in the main types of activity in 2017

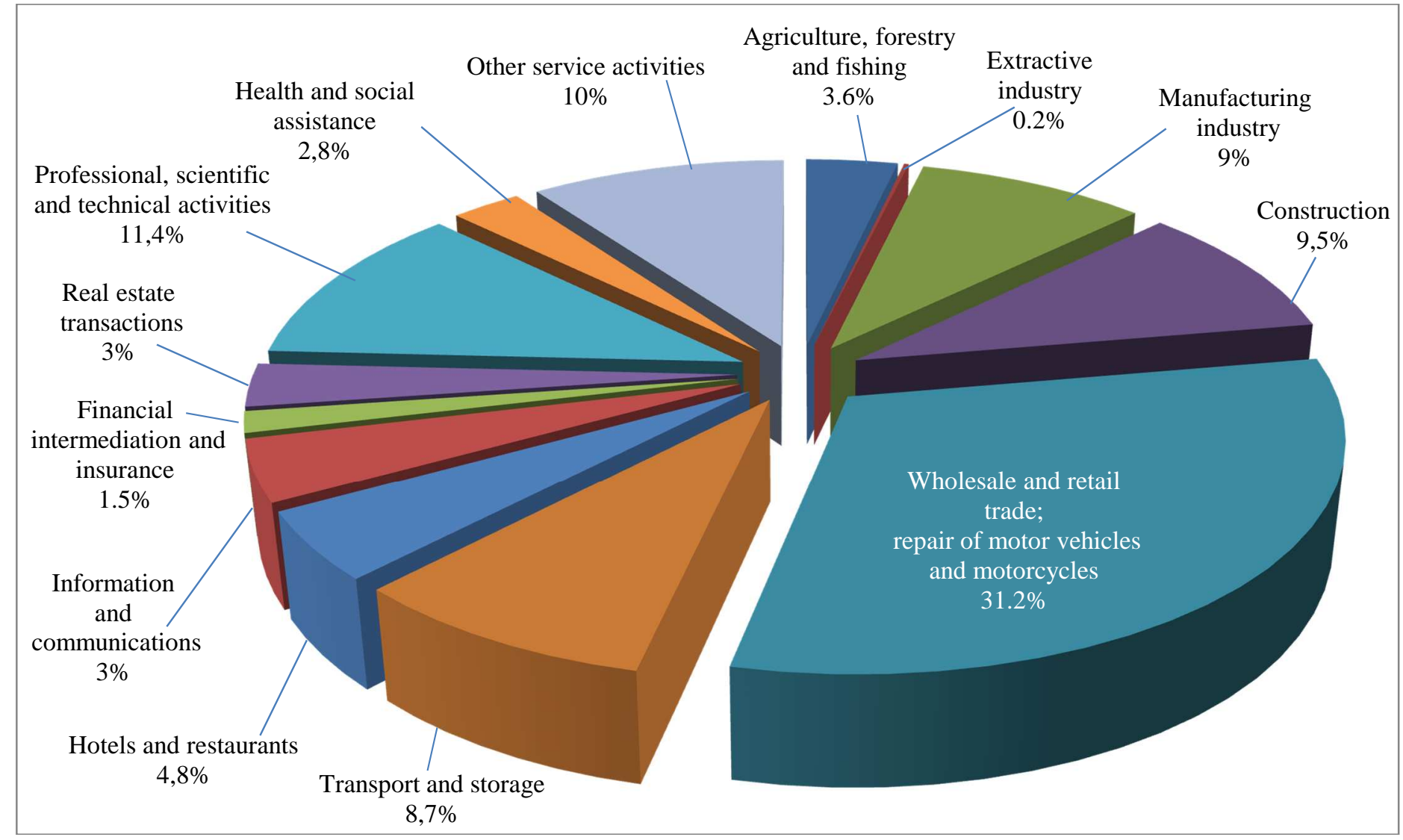

Source: National Institute of Statistics 
A significant share of the existing SMEs operates in the field of trade and services related to the automotive industry, but the values of these weights decreased by $6 \%$ in 2017 compared to 2010. It is worth noting that the weights of SMEs in the profile of the main categories of activities have remained relatively constant during the two years analyzed, which justifies the assertion that in Romania the SME sector has a relatively constant representation. This situation brings to Romania a weak point in terms of the performance of state policies to support and contribute to the diversification of this important business sector of the economy. Not only does the SME sector have no significant representation in the field of services, but the agricultural sector is not exploited to its full potential. Another confirmed reality among developed countries is the power and significant role of financial intermediation and insurance services in supporting a favorable and sustainable climate in the SME sector. Unfortunately, this activity occupies a significant share in the profile of the main activities related to small and medium-sized companies in Romania. The value of about $1 \%$ represented by this activity highlights the need for reforms in the field of financial intermediation and insurance, measures that will contribute to increasing the competitiveness of companies operating in this sector.

In view of the large share that the SME sector has in the total number of companies in the country, it is necessary that the governmental responsibility should increase, and the macroeconomic policies implemented at the state level should be oriented mainly on this vital sector of the national economy. Supporting small business also involves efficient financing of the entrepreneurial sector, a sector that can be the engine of modernizing and increasing economic competitiveness with a decisive role in ensuring a competitive economy [5]. In the context of the market economy and the internationalization of economic activities, the development of entrepreneurship is an essential factor in promoting the technological initiative, innovation and not least an important source for creating new jobs. It is also necessary to continue the structural reforms regarding the legal and organizational support of the small business, ensuring the promotion and financing of the entrepreneurial sector, as well as supporting the participation of small enterprises in the export trade.

\section{CONCLUSIONS AND FURTHER RECOMMENDATIONS}

The particular importance that small businesses represent in the context of economic growth derives from the flexibility and the rapid capacity to respond to changes in the business environment and market demands. This also explains why investments in this sector of SMEs bring higher incomes than investments in large enterprises. It should be emphasized that small businesses are often oriented towards meeting the needs of the local market and using local labor force, this aspect having a direct impact on reducing unemployment.

From the quantitative and qualitative analysis of the main indicators that characterize the activity of the SMEs, we have been able to identify some weaknesses and strengths of Romania in this field, the result of the study contributing to the foundation of some recommendations regarding the future directions of action of the state to support development of the small business sector.

The main recommendations regarding the future directions of Romania in the SME sector concern the following priority areas:

- developing consulting services in the field of entrepreneurship in order to substantiate well-documented business plans so as to increase the quality of projects benefiting from state or EU funding. This would ensure the efficiency and sustainability of the business environment in the medium and long term by opening or setting up new viable and capable companies to meet the market demands;

- improve access to finance by granting to all banks, regardless of size, the possibilities to easily implement loans from the EIB or EU instruments;

- to identify less developed sectors or branches but with great potential and to create a national strategy to support the setting up of SMEs in those under-exploited areas;

- orientation of small business towards services and the production of consumer goods;

- facilitating the access of SMEs to financing by participating in venture capital markets or through measures designed to encourage investors to finance the opportunities offered by SMEs;

- giving more attention to human capital by adapting the educational system to the demands of the labor market with an impact on increasing the competitiveness of labor and employment in the economy.

- continuing the structural reforms meant to support the mechanisms of the competitive economy.

Considering Romania's status as an EU member state, the steps to improve the business environment must be continued in order to ensure an optimal climate of the competitive economy. In this regard, it is recommended to continue aligning the economic policy objectives in the SME field with the priorities of the Europe 2020 Strategy. Ensuring a sustainable management in the SME field is an essential condition of the market economy and is a prerequisite for an efficient and successful collaboration between the public and the private environment. The existence of a developed SME sector also represents the existence of an efficient state management characterized by efficient economic, regional, investment and innovation policies.

\section{REFERENCES}

1. Ana Maria Marinoiu, Alina Irina Popescu, Sustainability and innovation in the international business environment, The Publishing House of the Academy of Economic Studies, Bucharest, (2019).

2. Claudis Sima, European funding for SMEs, Rezon Media Grup Publishing House, Bucharest, (2018).

3. Jim Collins, Business excellence, Publishing House: Curtea Veche, (2017).

4. Alexandra Irina Danciulescu, Risk management within SMEs in the current context of globalization and internationalization of companies, University Publishing House, Bucharest, (2015).

5. $\mathrm{Ng}, \mathrm{H}$. and Kee, D., Entrepreneurial SMEs Surviving in the era of Globalization: Critical Success Factors, Emerald Publishing Limited, pp. 75-90 (2017). 